\title{
El papel del campesino colombiano en los procesos de urbanización del país
}

The role of the Colombian farmers in the process of development of the country

\section{Resumen}

El presente artículo se basa en el trabajo de investigación "Postulaciones políticas en la novela colombiana del siglo xx", de la Universidad Cooperativa de Colombia, sede Buca-

ramanga, 2009, que se ha realizado en los dos últimos años a partir de la obra La casa de las dos palmas, para plantear una propuesta pedagógica a través de la transversalización de las áreas de español y sociales para estudiantes de noveno grado de los colegios públicos de Bucaramanga.

La obra La casa de las dos palmas escrita por Manuel Mejía Vallejo, a finales del siglo XX, relata el proceso de urbanización del país, en particular el que se vivió en la colonización antioqueña, que fue similar al vivido en otras regiones del país, además de la fundación de nuevas poblaciones en el país.

Palabras clave Análisis literario, campo, ciudad, costumbrismo, literatura colombiana.

Abstract

This article is based on the research work "Political proposals in the nine teenth century colombian novel" of Universidad Cooperativa de Colombia, Bucaramanga, 2009, that has been done in the past two years from the work La casa de las dos Palmas to raise a pedagogic proposal through the mainstreaming of Spanish and social studies for students in ninth grade of public schools in Bucaramanga. The book La casa de las dos Palmas written by Manuel Mejía Vallejo in the late twentieth century, relates country's urbanization process lived in the colonization of Antioquia, which was similar to that experienced in other regions of country.

Keywords Literary analysis, countryside, city, customs, Colombian literature.

\author{
Yuli-Paola Valbuena* \\ Diana-Carolina Moreno ${ }^{* * *}$ \\ Deyanira Restrepo ${ }^{\% \%}$ \\ Docente que avala el artículo: \\ Jairo Castro Neira ${ }^{\text {****** }}$
}

Recibido: 4 de marzo del 2011

Aprobado: 18 de abril del 2011

Cómo citar este artículo: Valbuena, YuliPaola; Moreno, Diana-Carolina y Restrepo, Deyanira (2011), "El papel del campesino colombiano en los procesos de urbanización del país", en Rastros Rostros, vol. 13, núm. 25 , pp. 80-86.

* $\quad$ Estudiante de Licenciatura en Educación Básica con énfasis en Humanidades, Lengua Castellana e Inglés de la Universidad Cooperativa de Colombia, sede Bucaramanga. Correos electrónicos: yulipaola.valvuena@campusucc.edu.co, yulipaito2008@hotmail.com

** Estudiante de Licenciatura en Educación Básica con énfasis en Humanidades, Lengua Castellana e Inglés de la Universidad Cooperativa de Colombia, sede Bucaramanga. Correos electrónicos: dianacarolina.moreno@campusucc.edu.co, nana_0607@hotmail.com

*** Estudiante de Licenciatura en Educación Básica con énfasis en Humanidades, Lengua Castellana e Inglés de la Universidad Cooperativa de Colombia, sede Bucaramanga. Correos electrónicos: deyanira.restrepo@campusucc.edu.co, babypretty51@hotmail.com

***** Licenciado en Idiomas de la Universidad Industrial de Santander. Magíster en Semiótica (Tesista) de la Universidad Industrial de Santander. Docente de la Universidad Cooperativa de Colombia, sede Bucaramanga. Correo electrónico:jairo.castro@campusucc.edu.co 


\section{Introducción}

l presente artículo se ubica dentro del $\checkmark$ proceso investigativo: "Postulaciones políticas de la novela colombiana del siglo XX" y pretende mostrar los resultados del análisis de la novela la Casa de las dos palmas de Manuel Mejía Vallejo, el cual fue desarrollado en tres capítulos: análisis teórico, análisis semántico y propuesta pedagógica. En el análisis teórico se habla de la obra literaria y de su contexto socio-cultural, religioso y político, además del autor, su vida y obra.

Los referentes teóricos que iluminaron el trabajo son la teoría de la sociocrítica de Claude Duchet (1991), la teoría de tiempo y narración de Paul Ricoeur, (1995), el periodo de la historia colombiana de la época en que se desarrolló la obra, y la historia de la novela colombiana en el siglo XX. El análisis semántico se desarrolló a partir de la teoría del pacto narrativo de Carolina Molina en su texto Como se analiza una novela. Teoría y práctica del relato I (2006). La propuesta pedagógica transversaliza las áreas de español y sociales para estudiantes de noveno grado de los colegios públicos de Bucaramanga.

Esta investigación se hace pertinente en la actualidad debido a la situación política y social que vive el país. Muchos de nuestros abuelos conocen la historia de la construcción de los pueblos colombianos, del paso del campo a la ciudad, pero los jóvenes difícilmente se acercan a esta realidad. El periodo de los ochenta se caracterizó por la turbulencia y confusión de los hechos de violencia que se venían presentando en el país, producto de los nuevos ingredientes introducidos a la guerra: narcotraficantes, militares, paramilitares, pandilleros o sicarios y bandas de delincuencia común, factores que dan un giro diferente al "conflicto político armado tradicional”. Los diferentes enfrentamientos entre la gama de grupos conformados no apaciguan el clima de zozobra vivido en el país, por el contrario, alteran los ánimos y se reafirma la guerra civil no declarada, oficialmente, en la nación.

En su forma de escribir, Mejía Vallejo muestra, entre el verso y la prosa, la situación colombiana, a nivel económico, social y especialmente político, teniendo como fuente la familia antioqueña y la semejanza que tiene con las de otros lugares del país, especialmente en las provincias. En Antioquia se instalaron pequeños y medianos propietarios, una colonización espontánea de gente sin bienes de fortuna, desarrollando trabajo comunitario, en familia. En la admirable literatura testimonial, más reciente, después de 50 años de silencio, gentes del pueblo que fueron protagonistas de una historia impactante han empezado a reconstruir su destino mediante un lenguaje vivo y lleno de revelaciones.

Dentro del ambiente pedagógico, la investigación se traslada al aula para comparar la forma en que se enseña la historia colombiana, planteando la lectura y análisis de esta obra al transversalizar las áreas de la lengua castellana y sociales, y dando un enfoque constructivista a la educación para incentivar en los jóvenes de noveno grado las ganas de leer y escribir textos propositivos con criterios políticos. De esta forma ellos participan en el foro propuesto con los colegios públicos de Bucaramanga, en el cual expondrán los textos críticos-argumentativos que construyen a partir del análisis literario de la obra y la situación social de los campesinos de esta época.

Otro aspecto importante es que este trabajo investigativo mejorará la capacidad de lectura especialmente de textos literarios; Iser (1991) dice que el significado no está en el texto, sino que se construye en el proceso de lectura. El texto literario produce una evocación de lo conocido (el pasado), pero también conduce a una negación de los esquemas mentales.

A nivel personal, la lectura y análisis de esta obra permite descubrir todo lo vivido por anteriores generaciones y las razones por las que hoy muchos lugares del país viven en el atraso y el olvido; además, esta



Revista Rastros Rostros - Volumen 13, Número 25 - enero-junio 2011 
investigación tiene el objetivo de recuperar el amor por la patria y el compromiso de los maestros en formación de empezar a cambiar la historia de Colombia.

\section{Metodología}

El proyecto "La casa de las dos palmas: el papel del campesino en los procesos de urbanización del país” se inició a partir de la realización del anteproyecto, junto con la reseña de la obra; luego se elaboraron tres capítulos que fueron guiados por los objetivos específicos del anteproyecto. Los capítulos fueron los siguientes: el análisis teórico, que se dividió en los referentes teóricos, el marco histórico y los espacios de experiencia del autor y la obra; el análisis semántico, formado de la configuración del papel de la mujer antioqueña dentro de la obra y la teoría del pacto narrativo; y, por último, la propuesta pedagógica con la teoría de la pedagogía literaria y el pensamiento crítico, que forman el proyecto de aula planteado como secuencias didácticas.

A continuación se hará una síntesis de las partes más importantes de cada uno de los capítulos del proyecto de investigación, el cual está enmarcado dentro del macroproyecto "Postulaciones políticas de la novela colombiana de finales del siglo XX".

El capítulo I es el análisis teórico que comprende en su primera parte los referentes teóricos, la teoría de la sociocrítica de Claude Duchet, que señala que: "la sociocríitica es un estudio social y textual al mismo tiempo, es decir, la sociocrítica lee lo social presente en el texto" (Duchet, 1991, p. 56).

De acuerdo con lo anterior, la sociocrítica permite llevar a un texto lo esencial de una sociedad, mostrar la parte social en relación con la literatura de acuerdo con el pensamiento del autor y la interpretación del lector. Es decir, se tienen en cuenta elementos de la realidad social para complementarla con la ficción creada por el escritor; los problemas e intereses de un grupo social, las ideologías, las culturas, los estilos de vida, que en conjunto caracterizan los personajes.
Claude Duchet forjó la expresión sociocrítica "para designar un conjunto de problemas, para nombrar, llenar, señalar un lugar aún desocupado: la socialidad de los textos, en particular del texto novelístico. Práctica, producto, objeto social, la novela es lo primero porque ocupa un lugar destacado en la circulación cultural de las ideas, de las imágenes, de las formas, de los estereotipos, de las configuraciones discursivas" (1991, p. 55). La novela ha sido un elemento clave de la formación del imaginario social, por lo menos antes de la aparición del cine y la televisión. Ésta ha sido una suerte de cantera de imágenes, de discursos, de palabras, de situaciones, de modelos narrativos; un foco cultural muy poderoso.

El otro referente teórico principal de esta investigación es el planteado en el texto Tiempo y narración de Paul Ricoeur, quien dice que: "La mímesis I se relaciona con el autor, la mímesis II se relaciona con la obra y la mímesis III se relaciona con el lector” (1995, p. 119).

Comprender una historia es comprender a la vez el lenguaje del hacer y la tradición cultural de la que procede la tipología de las tramas. Es decir, en la trama de una obra literaria se ve implícita la cultura de un lugar y las acciones que en éste ocurren, en la mayoría de las ocasiones una historia se ve recreada por parte del autor con distintas figuras literarias o situaciones producto de su imaginación. Según Ricoeur: "el conocimiento de la realidad aportado por la ficción del texto es planteado como un aprendizaje, es decir, un conocimiento que no se agota en el objeto sino que se actualiza permanentemente en la experiencia compartida" (1995, p. 145).

Sólo el paso de un tiempo a otro, a través de la mediación poética del lenguaje es lo que permite apropiarse del tiempo, constituyendo así, no una sucesión abstracta de momentos indiferentes, sino una experiencia temporal, articulada y comunicable. Luego de ver los postulados de Duchet (1991) y Ricoeur (1995), se hará un breve relato de los hechos que sucedieron en la época que fue escrita la obra, permitiendo ver la 
incidencia de la historia y de la novela en el país, en la forma en que escribe Manuel Mejía Vallejo. El marco histórico se divide en la Historia de Colombia del siglo XX, centrándose en los hechos que marcaron la situación de la población campesina y la historia de la novela del siglo XX, que marca la forma de escribir del autor antioqueño que se está analizando en el presente proyecto. De esta forma, dentro de la Historia de Colombia del siglo XX se puede comentar lo siguiente: a través del tiempo, los campesinos colombianos han pasado por distintas situaciones en las que se les ha intentado dar estabilidad en la posesión de tierras y el aprovechamiento de las mismas, para garantizarles una mejor calidad de vida. Hasta mediados de los años sesenta, "el recurso tierra urbana no se reconoce aún como un recurso limitado, luego a mediados de 1955-1965 el primer impulso urbanizador, fruto de la violencia en el campo no encuentra mayores obstáculos legales para su acomodamiento urbano, dado que no existen reglamentos muy precisos que lo regulen" (Arango, 1982, p. 3).

En la segunda parte del marco histórico, se muestra la historia de la novela del siglo XX. Eduardo Santa, en pleno apogeo de la novela de la violencia, siendo él uno de los practicantes de la novelística de la violencia, después de plantear que la labor revolucionaria del novelista consiste en su habilidad para preparar en el ánimo del lector las intrínsecas condiciones de la inconformidad con el ambiente descrito, manifiesta esta consigna que siguen muchos escritores al abarcar el tema de la violencia: "la labor revolucionaria del escritor está en su habilidad para captar lo feo, lo grotesco, lo vituperable y vil de una época histórica, de un ambiente o de una colectividad o grupo social, a tal punto que logre comunicar al lector -en un proceso a veces imperceptible o insensible el deseo de transformar lo vil en grandioso, lo grotesco en amable, lo vituperable en placentero" (1955, p. 15).

De esta manera, se fue estableciendo en Colombia, hacia la década de 1960, la novelística de la "violencia” con novelistas como García Márquez, Cepeda Samudio y Gustavo Álvarez Gardeazábal. En esta misma época, muchos de los países latinoamericanos experimentaban el proceso de la transformación narrativa, en el cual la problemática común era cómo superar la antigua forma de concebir la novela como instrumento para convertir la novela en arte. Muchos novelistas emprendieron la búsqueda de una nueva novelística, y sólo los que llegaron a dar una respuesta a través de las mismas creaciones lograron converger en el fenómeno llamado el boom de la literatura latinoamericana. En este sentido, el caso colombiano que se plasma en este trabajo servirá como un ejemplo ilustrativo para profundizar en el inagotable tema de la evolución de la novela en América Latina.

En la parte final del primer capítulo se encuentran los espacios de experiencia que comprenden la relación del autor con el tiempo en el que vivió y escribió la obra, y la relación de su vida como escritor con las características de sus obras. Manuel Mejía Vallejo nació el 23 de abril en Jericó, pueblo del suroeste de Antioquia, Colombia, aunque toda su infancia la vivió en Jardín, municipio vecino de Jericó. Ambos municipios están ubicados en una de las regiones más ricas de producción de café del país y están rodeados de altas montañas. Sus padres fueron Alfonso Mejía Montoya, hacendado y hombre emprendedor y Rosana Vallejo, artista natural y experta ceramista. Manuel fue el quinto de una familia de doce. En la educación de su época se preocuparon mucho por capacitarse en oficios, por la necesidad de crear empresa y tener mano calificada para la producción eficiente en sus industrias. La lírica antioqueña está principalmente en la poesía popular, coplas y canciones bañadas de ternura, delicadeza, u odio y desprecio, son ellas el canto del trabajo que escribió el pueblo con el sudor de su frente, la sangre de sus venas y el llanto de sus ojos; están las huellas de su tristeza, su gozo, su

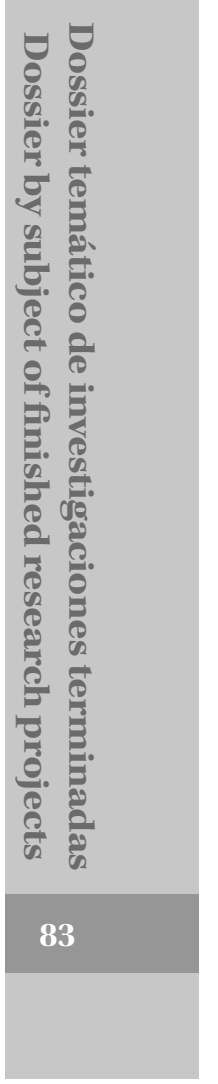

Revista Rastros Rostros - Volumen 13, Número 25 - enero-junio 2011 
altivez, su amor al arado, al mazo, sus bríos, sus alientos y esperanzas del mañana.

En lo concerniente al segundo espacio de experiencia, que corresponde a la vida de Mejía Vallejo como escritor y lo relevante de su obra, Luis Marino dice que: "Manuel Mejía Vallejo representa la vertiente andina de la narrativa colombiana contemporánea, caracterizada por un mundo de símbolos que van perdiéndose en el recuerdo de la montaña" (2004, p. 15). Mejía Vallejo ideó el pueblo de Balandú, y confiesa que escribe porque entiende mejor los fenómenos al irlos describiendo. A los 13 años ya le escribía a su madre largas cartas con un estilo sorprendente. Hizo estudios de pintura y escultura en la escuela de Bellas Artes de Medellín, sin que llegara a terminar, pues descubrió que su oficio eran las letras. Posteriormente ejerció el periodismo en diferentes países de América. Como periodista escribía en promedio 30 páginas diarias, lo cual demuestra la consagración y la aptitud innata de este autor. A la edad de 22 años ya había escrito su primera novela, titulada La tierra éramos nosotros. Su madre se la entregó al grupo de los Panidas, coordinado por León de Greiff, sin que Mejía lo supiera. La lectura de esta novela causó una gran impresión entre el grupo y fue así como se publicó, en 1945. Durante muchos años, Mejía Vallejo fue profesor de literatura en la Universidad Nacional, sede Medellín.

Jaime Jaramillo afirma que: "en su más inmediata significación histórica y sociológica, Balandú se presenta como un auténtico microcosmos de la provincia colombiana, en especial la de cultura paisa" (1989, p. 1). Pero sería una lectura unilateral y empobrecedora considerar que la temática rural y aldeana, en especial de las dos últimas obras mencionadas de Manuel Mejía Vallejo, las convierte en una simple extensión de la literatura costumbrista, cuyo legado se verá en nuestra literatura, con brotes de cierto anacronismo nacional, hasta nuestros días. De verdad, la literatura del escritor que es objeto de estas notas presupone, como un legado personalmente asimilado y refigurado, muchos rasgos de la rica tradición oral del pueblo antioqueño, captada en un trasegar antiguo de fondas y caminos, cuya sabrosa habla se infiltra, a lo largo de toda su obra, en muchas de las voces que de ella emergen. Pero su obra de ficción no sería comprensible en su perspectiva, en el entrecruzamiento de tiempos y modos expresivos, en los diferentes niveles de escritura, en la estructura interna de sus más notables libros, sin la decisiva referencia a los aportes de la novela contemporánea, en sus diversas vertientes.

En el segundo capítulo del proyecto, llamado análisis semántico, se presenta la configuración del papel de la mujer antioqueña en La casa de las dos palmas y la teoría del pacto narrativo. María Alejandra Villamizar (2005, p. 2) dice en su artículo “Qué define a las mujeres del siglo XX?”:

El siglo XX logró construir con dificultad, las respuestas a las preguntas reales de las mujeres sobre sus roles y avanzó en la elaboración de fórmulas para combinar los anteriores dilemas. Ha sido el siglo del sí, de la apertura, de la política, de la liberación y, por todo eso, también de la confusión. En el camino se ha acertado, hoy muchos escenarios del pasado son impensables, pero también se ha errado, se ha exagerado y se ha faltado. La superación de la mujer ha convertido en obsesión su perfección.

En la novela La casa de las dos palmas se plantea la situación de Evangelina, quien sufrió maltratos por parte de su marido. La relación de Evangelina y su madre se limitaba a la enseñanza de cómo debía ser una buena esposa, de forma que nunca tuvieron un diálogo en el cual se expresara la importancia de su dignidad como mujer. En esta obra también se encuentran otros tipos de mujeres como Isabel, una de las conquistas de Efrén Herreros, quién estaba muy enamorada de él, a pesar de que sabía no era la única en su vida. Ella se sentía como su verdadero y único amor.

En la obra de Manuel Mejía Vallejo se ve cómo, por ejemplo, Zoraida, a pesar de sus limitaciones, 
estaba deseosa de adquirir nuevos conocimientos, le gustaba disfrutar de las pequeñas cosas que ofrece la belleza de la naturaleza y aprendió infinidad de cosas que muchas veces personas con todos los sentidos no lo hacen; ella es un ejemplo de superación, empuje y verraquera como mujer antioqueña.

\section{Para Virginia Gutiérrez:}

El madresolterismo interclases es el resultado de las relaciones maritales esporádicas entre parejas de status sociales diferentes. La mujer pertenece como norma a un nivel más bajo que el del hombre. Este madresolterismo abarca zonas rurales y urbanas, en las zonas rurales es resultante de las presiones derivadas de la tenencia de tierra, en la servidumbre domestica, este fenómeno es de una fuerte evidencia. El madresolterismo en ellas resulta de relaciones dentro y fuera del estatus (1968, pp. 68, 69).

La situación que vivió Escolástica con Efrén Herreros tuvo como consecuencia el nacimiento de Juancho López. Ella estuvo sometida cuando era joven y servía en la casa a Efrén. Este es un claro ejemplo de una situación de madresolterismo en la sociedad antioqueña dentro de las zonas rurales: la sirvienta y el hacendado. Esta situación se dio en muchos hogares antioqueños y actualmente también ocurre, no sólo entre sirvienta y hacendado, sino en otras esferas de la sociedad: sirvienta-jefe, secretaria-gerente, empleada-jefe, entre otros.

El tercer capítulo correspondiente a la propuesta pedagógica está construido a partir de Elementos para una pedagogía literaria de Alfonso Cárdenas Páez (2004), los postulados de pensamiento crítico de María Poveda (2004) y los estándares de Lengua Castellana y de Ciencias Sociales (2010). Su desarrollo se presenta en el siguiente aparte de este artículo.

\section{Resultados}

En los estudiantes del grado noveno, se dan como posibles causas del bajo desempeño escolar el desinterés que muestran hacia el aprendizaje, ya que leer y escribir les parece tedioso y aburrido. El estudiante busca entonces métodos y herramientas de consulta que le facilitan la realización de sus tareas, como Internet, los resúmenes o el recurso de mandar a hacer sus trabajos, dejando de lado el uso de los textos literarios como forma de conectarse con el conocimiento de historias basadas en la realidad, que les beneficiarían, no sólo en su desempeño escolar, sino que posibilitarían un cambio de pensamiento, con miras a la adquisición de un pensamiento crítico que les permita ser agentes de cambio de su sociedad.

Para llamar su atención y desarrollar sus habilidades interpretativas se propone implementar el proyecto escolar "Foro municipal de estudiantes del grado noveno pertenecientes a colegios públicos de Bucaramanga”, en el cual se realizará la socialización de textos crítico-argumentativos basados en la novela La casa de las dos palmas.

En las ciencias sociales se debe fundamentar la búsqueda de alternativas a los problemas sociales que limitan la dignidad humana, para lo cual es importante forjar en niños y jóvenes posturas críticas y éticas, que sean expresadas en textos críticoargumentativos, partiendo de obras literarias, para generar la transversalización de las áreas principales como son la lengua castellana y las ciencias sociales. A los estudiantes, en la actualidad, se les debe motivar a la lectura crítica de obras literarias colombianas para que mejoren su producción lecto-escritora, para que conozcan cómo han sido los orígenes del país y para que tengan criterios para expresar sus opiniones, tomar decisiones acertadas en el ejercicio de la democracia, e incluso tener posibilidad de darle un giro a la historia de desigualdad social del país.

Alfonso Cárdenas Páez dice que:

La enseñanza de la literatura no ha cumplido el correspondiente papel en la educación, cuando los lineamientos del lenguaje la empobrecen a expensas del poder informativo y masificador de los medios de comunicación; por eso se deben formular propuestas pedagógicas centradas en la

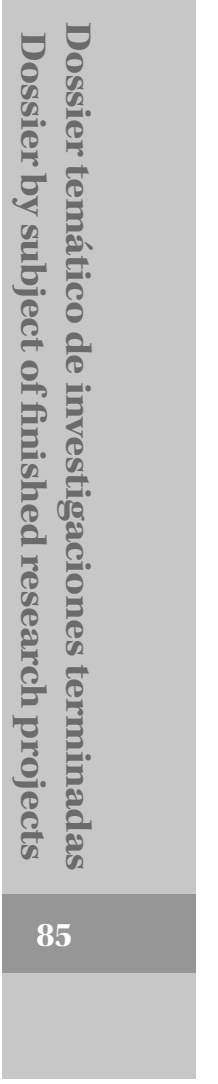

Revista Rastros Rostros - Volumen 13, Número 25 - enero-junio 2011 
formación integral de los estudiantes. La concepción de la literatura debe atender a su condición estética y artística, así como a la naturaleza del lenguaje y al poder creador del mundo que la caracterizan (2004, p 14).

En cuanto a la lectura de la obra literaria, ésta se debe abordar como una lectura crítica, atenta a las grandes líneas de sentido que la permean (Cárdenas 2004, p. 17). De acuerdo con estos postulados se fundamenta el proyecto de aula que busca mejorar la producción lecto-escritora de los estudiantes de noveno grado de los colegios públicos de Bucaramanga.

El proyecto de aula se realiza mediante el diseño, aplicación y evaluación de seis talleres de lectoescritura que permiten la producción de textos crítico-argumentativos por parte de los estudiantes de noveno grado.

\section{Conclusiones}

- Proporcionar espacios a los estudiantes de noveno grado para vivir la literatura en el ámbito escolar de una manera diferente, transverlizando áreas fundamentales como la lengua castellana y las ciencias sociales.

- Demostrar a los estudiantes la importancia que tienen sus pensamientos y la forma en que los pueden contextualizar para ser expresados en un texto critico-argumentativo, con el cual mejoran su proceso de aprendizaje lecto-escritor.

- Reconocer la importancia de la lectura de obras literarias colombianas con las cuales los estudiantes revivirán parte fundamental de la historia y darán sus aportes a través del análisis que hacen en sus textos críticos-argumentativos

- Despertar interés acerca de la vida de los Herreros, sus sueños, sus frustraciones, sus alegrías y sufrimientos, pues ésta es la manifestación misma del ser humano puesta en un paisaje rural. Esta obra refleja el inicio de la vida y de la "verraquera antioqueña", aunque debe entenderse que no se trata sólo de mostrar la vida en esa región de Colombia, sino de lo que es en esencia la fuerza del colombiano puesta al servicio de la supervivencia.

- El análisis de esta obra tiene vital importancia para reconocer que Colombia está en la necesidad de construir un orden social justo y equilibrado, de diseñar un proyecto económico, político y cultural a partir de la conciencia de sus posibilidades y limitaciones. Esto, partiendo de propuestas dadas por estudiantes universitarios que desean dar giros a la situación actual del país, dejando como inquietud hacia otras personas lo necesario que es abordar estas temáticas para conocer cómo ha sido la historia de nuestro país y la forma en que ha sido relatada en las grandes obras escritas, para mejor comprensión de los ciudadanos.

\section{Referencias}

Cárdenas Páez, A. (2004), Elementos para una pedagogía de la literatura, Universidad Pedagógica Nacional.

Duchet, C. (1991), Sociocríticas: prácticas textuales, cultura de fronteras, Rodopi, Ámsterdam.

Gutiérrez de Pineda, V. (1968), Familia y cultura en Colombia, Universidad de Antioquia, Medellín.

Mejía Vallejo, M. (1988), La casa de las dos palmas, Planeta, Bogotá.

Molina, C. (2006), Cómo se analiza una novela. Teoría y práctica del relato I, Universidad de Extremadura.

Poveda Fernández, M. "Pensamiento crítico”, en Revista de investigación e información filosófica, vol. 60, núm. pp. 226-228.

Ricoaeur, P. (1995), Tiempo y narración, México, Siglo XXI.

Villamizar, M. A. (2005, septiembre), ¿QQué define a las mujeres del siglo XX?", en Revista Credencial Historia, núm. 189, p.3 [en línea], disponible en http://www. banrepcultural.org/blaavirtual/revistas/credencial/ sept2005/mujeres_sigloxx.htm, recuperado: 9 de septiembre del 2010. 